\title{
Erythropoietin in Lupus: Unanticipated Immune Modulating Effects of a Kidney Hormone
}

\author{
Meghana Eswarappa ${ }^{1}$, Chiara Cantarelli ${ }^{2}$ and Paolo Cravedi ${ }^{\text {* }}$ \\ ${ }^{1}$ Department of Medicine, Icahn School of Medicine at Mount Sinai, New York, NY, United States, ${ }^{2}$ UO Nefrologia, Azienda \\ Ospedaliero-Universitaria di Parma, Parma, Italy
}

Systemic lupus erythematosus (SLE) is a multiorgan autoimmune disease with variable clinical presentation, typically characterized by a relapsing-remitting course. SLE has a multifactorial pathogenesis including genetic, environmental, and hormonal factors that lead to loss of tolerance against self-antigens and autoantibody production. Mortality in SLE patients remains significantly higher than in the general population, in part because of the limited efficacy of available treatments and the associated toxicities. Therefore,

OPEN ACCESS

Edited by: José Carlos Crispín,

Instituto Nacional de Ciencias Médicas y Nutrición Salvador Zubirán (INCMNSZ), Mexico

Reviewed by:

Zhiren Zhang,

Army Medical University, China Ana Barrera-Vargas,

Instituto Nacional de Ciencias Médicas y Nutrición Salvador Zubirán (INCMNSZ), Mexico

*Correspondence:

Paolo Cravedi

paolo.cravedi@mssm.edu

Specialty section:

This article was submitted to Autoimmune and Autoinflammatory

Disorders,

a section of the journal

Frontiers in Immunology

Received: 05 January 2021

Accepted: 24 February 2021

Published: 16 March 2021

Citation:

Eswarappa M, Cantarelli C and

Cravedi $P$ (2021) Erythropoietin in

Lupus: Unanticipated Immune

Modulating Effects of a Kidney

Hormone.

Front. Immunol. 12:639370.

doi: 10.3389/fimmu.2021.639370 novel targeted therapies are urgently needed to improve the outcomes of affected individuals. Erythropoietin (EPO), a kidney-produced hormone that promotes red blood cell production in response to hypoxia, has lately been shown to also possess nonerythropoietic properties, including immunomodulatory effects. In various models of autoimmune diseases, EPO limits cell apoptosis and favors cell clearance, while reducing proinflammatory cytokines and promoting the induction of regulatory $T$ cells. Notably, EPO has been shown to reduce autoimmune response and decrease disease severity in mouse models of SLE. Herein, we review EPO's non-erythropoietic effects, with a special focus on immune modulating effects in SLE and its potential clinical utility.

Keywords: erythropoietin, SLE, immunology, lupus, T cell, Treg

\section{INTRODUCTION}

Systemic lupus erythematosus (SLE) is a complex autoimmune disorder with multiorgan involvement. Interactions amongst genetic, hormonal and environmental factors lead to immune dysregulation and loss of tolerance to self-antigens, with consequent autoantibody production, inflammation, and tissue damage (1). SLE is characterized by a relapsing-remitting course with a wide spectrum of clinical presentations, including - but not limited to-cutaneous, articular, hematologic, pulmonary, neurological and renal complications. In particular, the prevalence of neurological manifestations, both of the central and peripheral nervous system, ranges between 14 and $95 \%$ and is associated with worse outcomes and higher mortality rates (2). The pathogenesis of neural disease in SLE remains unclear, but it likely involves a direct role of autoantibodies, inflammatory cytokines and chemokines, and brain blood barrier dysfunction (3). Renal disease affects between 28 and 74\% of SLE patients and is also associated with increased mortality (4-6). Despite treatment, a substantial percentage of SLE patients still develops end stage kidney disease (ESKD) and disease may recur after kidney transplantation $(7,8)$.

Available therapeutic options for SLE have limited efficacy and are burdened by significant toxicities. Therefore, new, hypothesis-driven therapies are needed to improve the outcomes of individuals with SLE. 


\section{SLE Pathogenesis}

Our understanding of SLE pathogenesis is still incomplete, but the following mechanisms are thought to play a major role. Defective clearance of debris from apoptotic cells exposes nuclear antigens, which initially triggers an innate inflammatory response via activation of toll-like receptors (TLR) and then bolsters T cell and B cell responses against autoantigens (9, 10). B cells present autoantigens to $\mathrm{T}$ cells, produce autoantibodies, and promote local inflammation. The autoantibodies bind to selfantigens and form immune complexes in various organs, further fueling the autoinflammatory response through the activation of complement and the recruitment of FcyR- and TLR-expressing innate immune cells. In turn, these cells release proinflammatory cytokines and chemokines, sustaining leukocyte infiltration and activation and formation of lymphoid aggregates, leading to organ damage $(10,11)$.

\section{Dendritic Cells and Macrophages}

Multiple abnormalities in dendritic cells (DCs) have been identified in SLE patients. In particular, plasmacytoid DCs (pDCs), responsible for secretion of high levels of type I interferon (IFN) via TLR7 and TLR9 stimulation, are increased in patients with SLE (12). Sustained production of type I IFN by pDCs in response to immune complexes represents a hallmark of SLE (13). Importantly, massive pDCs infiltrates are found in renal and skin lesions of SLE patients (14). This, together with the observation that ablation of these cells in lupus-prone mice reduces autoantibody production and lupus nephritis disease severity (15), supports the role of pDCs in the pathogenesis of SLE. Increase in $\mathrm{pDCs}$ is paralleled by a decline in conventional DCs (cDCs) in peripheral blood of SLE patients (16). These DCs are involved in maintaining self-tolerance and their reduction leads to an imbalance in DC subsets that favors a proinflammatory environment $(17,18)$.

Impaired clearance of apoptotic cell debris is a central pathogenic mechanism in the development of SLE. Defective clearance of apoptotic cell debris promotes release of autoantigens and autoreactive B cell stimulation, which leads to loss of tolerance and generation of autoantibodies. Consequent immune complex formation and deposition results in organ damage (19). As macrophages are a key cell subset in the clearance of apoptotic debris, it is not surprising that defective macrophage activity contributes to the pathogenesis and correlates with disease severity (20). Macrophage infiltrates in the kidney represent a strong prognostic biomarker for progression of lupus nephritis and correlates with the disease activity index (21).

\section{B Cells}

The role of B cells in the development of SLE has recently raised interest, not only for their ability to produce autoantibodies that lead to organ damage, but also for complex interactions with other cell types. Immune phenotypic studies showed abnormalities in the proportion of different $B$ cell subsets in SLE individuals. In particular, B cell lymphopenia with reduced numbers of naïve $\mathrm{B}$ cells and an increase in circulating classswitched memory B cells, plasma blasts and plasma cells is observed and correlates with disease activity (22).

Under the influence of genetic susceptibility and environmental factors, B cells in SLE patients show increased activation, as documented by active $\mathrm{B}$ cell receptor (BCR) signaling with increased phosphorylation of PI3K and AKT-1 and abnormal phosphatase activity (23), increased production of cytokines IL-6 and IL-10, constitutive expression of costimulatory molecules that affect $\mathrm{T}$ cell function and antigen presenting cells (APCs) (24), and loss of tolerance.

\section{T Cells}

Murine and human data converge to indicate that SLE is associated with defective and/or decreased numbers of regulatory $\mathrm{T}$ cells (Treg), which normally act to control conventional $\mathrm{T}$ cells (Tconv) and promote self-tolerance (25). Tconv in SLE individuals also display abnormalities that are likely the result of primary defects and the consequence of the proinflammatory environment. $\mathrm{T}$ cell abnormalities include altered activation signaling pathways, increased expression of pro-migratory markers, and upregulation of co-stimulatory CD40 ligand, contributing to B-cell activation. T cells from SLE patients also show an altered cytokine profile, including decreased transforming growth factor beta (TGF- $\beta$ ) and IL-2, and increased IL- 6 and IL-17 expression, which may contribute to the imbalance in T cell subsets $(26,27)$.

In particular, increased IL-17 and decreased IL-2 levels account for the higher Th17/Th1 ratio reported in SLE compared to healthy controls (28). Altered IL-2 production is also associated with Treg dysfunction and further promotes expression of IL-17, with a decreased Treg/Th17 ratio, which is detectable not only during flares, but also when the disease is in remission $(29,30)$. SLE patients show increased Th17 cells in peripheral blood and in kidney and skin lesion infiltrates, as well (31). SLE patients also display an imbalanced Th1/Th2 ratio, which is thought to play a major role in disease pathogenesis. Plasma levels of IL-10, a main driver of Th2 differentiation, are significantly increased and correlate with disease activity (32).

\section{EPO and EPO Receptors}

Erythropoietin is a glycoprotein initially discovered for its role in stimulating red blood cell production. More recently, evidence has accumulated indicating that EPO also displays nonerythropoietic properties. Interstitial fibroblasts in the kidney produce a basal level of EPO which binds to receptors on erythroid progenitor cells in the bone marrow to maintain a steady red blood cell mass $(33,34)$. Tissue hypoxia increases EPO production by stabilizing the Hypoxia Inducible Factor (HIF) transcriptional complex and activating EPO gene transcription (35).

Studies have identified two distinct EPO receptors. One is a homodimer receptor consisting of two EPO receptor (EPOR) monomers. Activation of this homodimer on erythroid progenitor cells triggers downstream signaling via JAK2 and subsequently STAT5, MAPK and PI3K pathways (36) which maintains erythropoiesis. The other receptor is a heterodimer, 
consisting of an EPOR monomer subunit and the $\beta$-common receptor CD131. EPOR-CD131 requires a higher concentration of EPO for activation and has been implicated in the nonerythropoietic, "tissue-protective" effects of EPO, due to its downstream effects that mediate suppression of proinflammatory cytokines and inhibition of apoptosis (37-39).

\section{EPO Derivatives}

Current FDA-approved indications for EPO include treatment of anemia associated with chronic kidney disease (CKD) or chemotherapy $(40,41)$. The increased risk of thrombosis and stroke associated with EPO administration (39, 40, 4244) prompted researchers to design asialoerythropoietin, a desialytated version of recombinant EPO notable for its shorter half-life which allowed for its neuroprotective effects with limited effects on erythrocyte mass (45).

An alternative approach was to develop molecules that selectively bind the EPOR-CD131 heterodimer and are therefore devoid of erythrogenic effects associated with the activation of the EPOR homodimer. This gave rise to carbamylated EPO (produced by carbamylation of lysine residues) and ARA290 (an 11-amino acid peptide that mimics EPO's helix B region), which have also been shown to maintain EPO's tissue-protective but not hematopoietic effects $(39,46,47)$.

\section{EPO's Non-erythropoietic Effects}

Over the last few decades, many non-erythropoietic effects of EPO have been identified in multiple organs. In the nervous system, EPOR expression has been detected in neurons, astrocytes, oligodendrocytes, microglia, and endothelial cells. Importantly, animal studies have shown that EPO has neuroprotective effects via neurogenesis, angiogenesis and antiapoptotic, anti-oxidative, and anti-inflammatory mechanisms (48). Although one clinical trial of EPO in the treatment of acute ischemic stroke found that EPO administration within $6 \mathrm{~h}$ of symptoms was associated with increased mortality (49), another trial suggested that EPO administration post-acute ischemic stroke in non-tPA (tissue plasminogen activator) candidates was associated with improved long-term neurological outcomes (50). EPO showed promising neuroprotective effects also in animal models of autoimmune optic neuritis (51), setting the basis for a clinical trial in humans (NCT01962571) (52). Further ophthalmological effects have been noted, including protection against retinal degeneration (53-55).

In the cardiovascular system, both endothelial cells and cardiomyocytes express EPORs. In experimental studies, EPO protects against cardiac ischemic injury by decreasing apoptosis and inflammation, and by promoting neovascularization (56). However, clinical trials of EPO administration after myocardial infarction (MI) have reported mixed results $(57,58)$ and a meta-analysis on 1,336 patients showed no improvement in infarct size, left ventricular function, or mortality when EPO was administered in patients undergoing percutaneous coronary revascularization post-MI (59).

EPOR has also been localized in renal tubular and mesangial cells (60). In animal models of kidney injury, such as ischemicreperfusion injury, erythropoiesis stimulating agents (ESA), including EPO derivatives, have improved disease severity via anti-apoptotic effects $(61,62)$. However, this beneficial effect has largely not been reflected in clinical trials. A meta-analysis of clinical trials found no clear benefit to ESAs in the development of acute kidney injury primarily following cardiac surgery, in renal transplant outcomes, or in CKD progression after anemia correction (63).

Therefore, tissue-protective effects of EPO have been largely demonstrated in numerous models of organ injury, but their clinical translation has provided inconsistent results, possibly as consequence of suboptimal dosing and timing. Whether selective activation of non-erythropoietic EPOR would improve safety/efficacy profile of EPO is worth investigating.

\section{EPO's Anti-oxidative and Anti-apoptotic Effects}

Oxidative stress contributes to tissue damage in the brain, kidney, heart and other organs. The discovery that EPO has direct and indirect anti-oxidative effects supports its use as a tissueprotective molecule. Anti-oxidative properties of EPO are in part independent from its role in countering apoptosis. EPO increases gene expression of Heme-Oxygenase 1 and other anti-oxidative enzymes, like superoxide dismutase, catalase, and glutathione peroxidase, directly on the cells, without the involvement of erythroid cell progenitors (64).

Several studies in different disease models and tissues identified the JAK2-STAT-Bcl2 pathway as one of the main antiapoptotic mechanisms of EPO, through the induction of antiapoptotic molecules, $\mathrm{Bcl}-2$ and $\mathrm{Bcl}-\mathrm{Xl}$, and the inhibition of proapoptotic molecules, Bax and Bak (38). In erythroid cells, EPOEPOR interactions prevent apoptosis through STAT5 signaling (65). In a murine model of acute encephalopathy due to cerebral malaria, EPO was associated with a dose dependent improvement in survival, together with a significantly reduced number of apoptotic cells (66). In a middle-cerebral artery model of ischemic injury in rats, EPO rescued neurons from apoptosis in a timedependent manner, through activation of extracellular signalregulated kinases and PI3K (67). Furthermore, EPO has been noted to exert direct protective effects on pancreatic $\beta$ islet cells in diabetes mouse models (68), and, in neonatal porcine islet cells, EPO's anti-apoptotic effect occurs through upregulation of Bcl-2 mRNA and downregulation of Bax and caspase-3 mRNA (69).

\section{EPO's Immunomodulatory Effects}

\section{Innate Immunity}

Erythropoietin's immunomodulatory activity has been demonstrated in both innate and adaptive immune pathways (70) (Table 1). In animal models of various autoimmune diseases, EPO reduced disease severity and was associated with decreased levels of proinflammatory cytokines. In a rat model of experimental autoimmune encephalomyelitis, EPO administration resulted in a dose-dependent delay in disease onset and decreased disease severity, as well as decreased inflammatory cells including macrophages, microglia, dendritic cells and monocytes. In this model, EPO also delayed the rise in tumor necrosis factor (TNF) levels and decreased the peak of IL-6 levels in the spinal cord (72). Nairz et al. 
TABLE 1 | Role of various cell subsets in SLE pathogenesis and effects of EPO.

Role in SLE

\section{Innate Immune cells}

Dendritic cells

cDCs are reduced, favoring a proinflammatory environment. pDCs produce high amounts of type I IFN that stimulate B cell proliferation, inflammation and loss of tolerance, promoting SLE development.

\section{Macrophages}

Macrophages have impaired function and cell clearance ability. Kidney macrophage infiltrates correlate with disease activity

\section{Adaptive Immunity}

Th1

SLE patients show altered cytokine profile, including decreased IL-2 plasma levels, which contribute to the imbalance in T cell subsets

Th2

IL-10 plasma levels, main drivers of Th2 differentiation, are increased and correlate with SLE disease activity

Th17

Th17 are increased and promote inflammation and tissue damage. These cells are found in kidney and skin infiltrates

Treg

Treg are decreased or defective, contributing to a proinflammatory environment and loss of self-tolerance

\section{B cells}

B cells produce autoantibodies and function as defective APCs that mediate $T$ cells' loss of tolerance
EPO effects
- In mice with cerebral malaria, EPO inhibits DCs differentiation and their expression of CD80, CD86, and TLRs (71)

- EPO reduces number of DCs in rat EAE model (72)

- EPO inhibits NF-kB and reduces expression of pro-inflammatory genes (Nos2, TNF- $\alpha$, and IL-6) in mice (73)

- EPO downregulates the expression of inflammatory cytokines by macrophages (71)

- In pristane-induced lupus-like murine model, EPO increases phagocytosis of apoptotic cells by macrophages and reduces accumulation of dying cells (74)

- EPO reduces Th1 proliferation, without affecting cell survival (75)

- EPO reduces Th1 in MRL/Ipr mice (76)

- EPO decreases Th1 in rats with EAN (77)

- EPO promotes Th2 differentiation in rat model of EAN (77)

- It increases Th2 cells in MRL/lpr mice (76)

- EPO prevents RORC expression and Th17 induction (78)

- It promotes Th17 conversion into Treg (78)

- EPO reduces Th17 in MRL/lpr mice and in pristane-induced SLE in mice $(76,78)$

- EPO promotes Treg induction through the release of active TGF- $\beta$ by APCs (79)

- EPO increases Treg in lymph nodes and in CNS in mice with EAE (72)

- EPO increases Treg in MRL/Ipr mice $(76,78)$

- EPO increases Treg in heart-transplanted mice (79)

- No direct effects of EPO on B cells have been reported.

EPO, erythropoietin; SLE, systemic lupus erythematosus; CDCs, conventional dendritic cells; pDCs, plasmacytoid dendritic cells; IFN, interferon; TLRs, Toll-like receptors; NF-kB, nuclear factor kappa-light-chain-enhancer of activated B cells; Nos2, nitric oxide synthase 2; TNF- $\alpha$, tumor necrosis factor $\alpha$; EAN, experimental autoimmune neuritis; RORC, RARrelated orphan receptor C; TGF- $\beta$, transforming growth factor $\beta$; Treg, regulatory T cells; APCs, antigen presenting cells; EAE, experimental autoimmune encephalomyelitis; CNS, central nervous system.

showed that EPO inhibits NF-kB and subsequently reduces expression of proinflammatory genes (Nos2, TNF- $\alpha$, and IL-6) in murine macrophages. Consistently, EPO administration reduced disease severity in experimental mouse models of autoimmune colitis. The anti-inflammatory effects of EPO, in contrast, impaired clearance of bacterial colonies in Salmonella typhimurium-infected mice, reducing animal survival (73). In mice with collagen-induced arthritis, EPO significantly reduced disease severity, oxidative damage, levels of proinflammatory cytokine TNF- $\alpha$ and chemokines MIP-1a and MIP-2, neutrophil infiltration, and the levels of chondrocyte apoptosis (80).

Both murine and human DCs express EPOR, suggesting that DCs can participate in the immunomodulatory properties of EPO. In DCs, EPO/EPOR signaling is more dependent on STAT3 than STAT5 (81). In studies of mice with cerebral malaria, EPO treatment significantly inhibited DCs differentiation and reduced expression of costimulatory markers CD80 and CD86, and TLRs (71).
Erythropoietin has also been demonstrated to play a role in macrophage clearance of apoptotic cells. The "find-me signal" sphingosine 1-phosphate released by dying cells activates EPO signaling in macrophages and, through upregulation of peroxisome proliferator activated receptor-y (PPARy), improves clearance of apoptotic cells (74). EPO-derivative ARA290 decreases expression of TNF- $\alpha$ and iNOS in LPS-treated macrophages and increases phagocytosis of apoptotic cells as well (82).

\section{Adaptive Immunity}

Both human peripheral blood $\mathrm{T}$ and $\mathrm{B}$ lymphocytes express EPOR (83), but the effects of EPO/EPOR interaction have been mainly characterized in $\mathrm{T}$ cells subsets.

\section{Th1}

Our previous experiments showed that EPO reduces Tconv proliferation in a dose-dependent manner, without affecting 
cell survival, and reduces Th1 polarization. These effects are mediated by the homodimeric EPO-R expressed on $\mathrm{T}$ cells that interferes with signaling downstream of the IL-2R $\beta$ chain, required for Tconv functions (75). The result is supported by the fact that ARA290 affects proliferation of anti-CD3/anti-CD28 mAb-stimulated CD4+ T cells (75).

\section{Th2}

Th2 differentiation of human naïve CD4+ T cells is not affected by EPO in vitro (75). Conversely, in vivo studies in experimental autoimmune neuritis model in rats show that treatment with EPO or ARA290 promotes Th2 differentiation and, together with Th1 and Th17 reduction and Treg increase, improves the disease $(77,84)$.

\section{Th17}

Th17 cells are strongly linked to autoimmunity and have a main role in SLE pathogenesis.

In vitro treatment with $\mathrm{EPO}$ of $\mathrm{CD} 4+\mathrm{T}$ cells under Th17 polarizing conditions, prevents Th17 master regulator RARrelated orphan receptor $\mathrm{C}$ (RORC) and Th17 gene expression and Th17 cell induction, even after exposure to high concentrations of $\mathrm{NaCl}$, a potent Th17 inducer, without affecting cell survival (78). EPO-EPOR interaction also prevents serine-threonine protein kinase-1 (SGK1) phosphorylation, required for RORC activity. SGK1 phosphorylation is dependent upon p38 mitogen-activated protein kinase, which is counteracted by EPO (78). In vitro experiments confirmed that EPO prevents Th17 induction and promotes the conversion of Th17 into Treg (78).

\section{Treg}

In vitro, EPO promotes the release of active TGF- $\beta$ from APCs. As TGF- $\beta$ is the main driver of naïve CD4+ T cell conversion into Treg, EPO thus promotes Treg induction. Importantly, while EPO inhibits Tconv proliferation, it does not affect Treg function once they are formed. Indeed, EPO uncouples signaling downstream of the IL- $2 \mathrm{R} \beta$ chain, which is already silenced in Treg by internal phosphatases, leaving IL-2R $\gamma$ chain signaling, crucial for $\mathrm{T}$ cells, unaffected (79).

EPO treatment increases Treg also in vivo in experimental models of autoimmune encephalitis $(85), \operatorname{SLE}(76,78)$ and organ transplantation (79). Importantly, the administration of EPO in doses required to correct anemia resulted in increased frequency of peripheral Treg in humans with CKD (79).

\section{EPO IN SLE}

\section{Anti-EPO and Anti-EPOR Autoantibodies}

Most EPO-related research in SLE has focused on the association between anemia and autoantibodies to EPO and EPOR. Autoantibodies to EPO in patients with SLE were first demonstrated by Tziuofas et al. (86). Since then, several studies have reported associations between the presence of anti-EPO antibodies and hematological (EPO or hemoglobin/hematocrit levels) and SLE-related parameters (SLE disease activity, complement levels or anti-dsDNA antibody levels) (86-88). Overall, these studies found an impaired EPO response in anemic
SLE patients, suggesting that autoantibodies may act as EPO antagonists $(87,88)$. However, other reports indicate that antiEPO antibodies may just interfere with serum EPO measurement rather than inhibit EPO activity (88).

Luo et al. (89) found that anti-EPOR antibodies in SLE patients were associated with more severe anemia, higher disease activity, augmented anti-dsDNA antibody levels, and lower C3 (increased complement consumption, a sign of disease activity). Notably, Hara et al. specifically looked at 46 patients with biopsyproven lupus nephritis and detected anti-EPOR antibodies in 18 patients. Those with anti-EPOR antibodies had significantly higher SLE disease activity and more severe anemia, suggesting that anti-EPOR antibodies have inhibitory function. Although these groups shared no differences in anti-dsDNA antibodies, complement levels, or renal function at time of biopsy, those with anti-EPOR antibodies had a higher disease activity index, and the presence of anti-EPOR antibodies was an independent risk factor for CKD progression (90).

Overall, anti-EPO and anti-EPOR antibodies correlate with SLE disease severity and may be associated with poor kidney prognosis, providing associative evidence that, by inhibiting EPOR immune modulatory effects, they may also fuel the autoimmune response.

\section{EPO's Effects in Murine SLE Models}

Different murine models have been developed to investigate pathogenic mechanisms of SLE and to identify potential new targets for therapy (91). While spontaneous models of lupus are principally used to study the genetic susceptibility to the disease, induced models help in defining the role of environmental factors in lupus pathogenesis and identifying mechanisms responsible for the onset and progression of disease. MRL/lpr mice, a spontaneous model of SLE, are characterized by a mutation in Fas gene and develop severe lymphoproliferative disease with lymphadenopathy, splenomegaly, proteinuric nephropathy and skin lesions (92). This strain also shows behavioral abnormalities and cerebritis that resemble neuropsychiatric involvement in SLE (93).

In 2018, Zhang et al. showed that MRL/lpr mice that received EPO for 10 weeks had less urinary protein, lower serum antidsDNA antibody levels, lower renal histopathologic scores with less IgG/C3 deposition in glomeruli, and decreased cytokine levels in the kidneys compared to controls. They also found that mice treated with EPO had fewer Th1 and Th17 cells and more Th2 and Treg cells (76).

Another study by Huang et al. (82) found that administration of EPO-derived helix-B peptide (ARA290) to MRL/lpr mice significantly decreased serum levels of antinuclear antibodies (ANA), anti-dsDNA antibodies, creatinine, cytokine levels (IL6, MCP-1, TNF- $\alpha$ ), renal deposition of IgG, and quantity of apoptotic cells in the kidney. Similar results were found in pristane-induced SLE mice. Importantly, these results were obtained without significant changes in erythropoiesis (82).

Mice that lacked EPOR selectively on macrophages developed lupus-like symptoms. At 55 weeks of age, the mice had significantly increased anti-dsDNA, antinuclear, and antiSmith antibodies, pathologic evidence of increased glomerular 
deposition of IgG, IgA, and C3, and increased glomerular size, cellularity and infiltration of immune cells compared to controls. They also developed higher proteinuria and serum creatinine and blood urea nitrogen (BUN) concentrations, along with increased IL-6, TNF- $\alpha$, IFN- $\alpha$, and IFN- $\beta$ levels, while TGF- $\beta$ decreased, suggesting that EPO/EPOR signaling in macrophages is key to maintaining self-tolerance (74).

Furthermore, in pristane-induced lupus-like murine model, EPO therapy increased phagocytosis of apoptotic cells by macrophages and correspondingly decreased accumulation of dying cells. These EPO-treated mice had decreased serum concentrations of anti-dsDNA antibodies, and of IL-6, MCP1 , and TNF- $\alpha$ levels. They also showed decreased glomerular IgG deposition and improved renal function, as indicated by decreased urinary albumin and serum creatinine (74). Mechanistically, these data have been linked to the S1P-EPO$\operatorname{PPAR} \gamma$ pathway in macrophages that is crucial for apoptotic cell phagocytosis (74).

As demonstrated by these studies, EPO treatment reduced disease severity in both pristane-induced and spontaneous MLR/lpr lupus models. More recently, it has been shown that these effects are linked to a direct action of EPO on T cells (78). In these models of lupus nephritis, in which Epo gene expression is reduced, EPO treatment prevents Th17 cell induction and increases the Treg/Th17 and Th2/Th1 cell ratio. In pristane-induced lupus nephritis, EPO deficiency selectively on $\mathrm{CD} 4+\mathrm{T}$ cell resulted in increased susceptibility to the disease (more proteinuria and severe renal involvement) and conferred resistance to the inhibitory effects of EPO on Th17 cell induction (78).

\section{IS EPOR A TARGET FOR FUTURE IMMUNE-MODULATING TREATMENTS FOR SLE?}

Erythropoiesis-stimulating agents are already currently used in patients with lupus nephritis for CKD-associated anemia. One cross-sectional study of 12,533 adult patients with ESKD

\section{REFERENCES}

1. Moulton VR, Suarez-Fueyo A, Meidan E, Li H, Mizui M, Tsokos GC. Pathogenesis of human systemic lupus erythematosus: a cellular perspective. Trends Mol Med. (2017) 23:615-35. doi: 10.1016/j.molmed.2017.05.006

2. McGlasson S, Wiseman S, Wardlaw J, Dhaun N, Hunt DPJ. Neurological disease in lupus: toward a personalized medicine approach. Front Immunol. (2018) 9:1146. doi: 10.3389/fimmu.2018.01146

3. Shaban A, Leira EC. Neurological complications in patients with systemic lupus erythematosus. Curr Neurol Neurosci Rep. (2019) 19:1-10. doi: 10.1007/s11910-019-1012-1

4. Alarcon G, McGwin Jr G, Petri M, Reveille J, Ramsey-Goldman R, Kimberly R, et al. Baseline characteristics of a multiethnic lupus cohort: PROFILE. Lupus. (2002) 11:95-101. doi: 10.1191/0961303302lu215xx

5. Cervera R, Khamashta MA, Font J, Sebastiani GD, Gil A, Lavilla $\mathrm{P}$, et al. Morbidity and mortality in systemic lupus erythematosus during a 10-year period: a comparison of early and secondary to lupus nephritis found that 4,288 (34\%) were receiving ESA therapy at the time of renal replacement therapy (RRT) initiation (94). However, no study has assessed the effect of EPO on renal outcomes in lupus nephritis in humans, including in earlier stages of active disease prior to progression to ESKD.

EPO has immunomodulatory properties that target several pathophysiological mechanisms of SLE. Specifically, EPO has been shown to attenuate proinflammatory cytokine levels, enhance apoptosis and cell clearance, and decrease proliferation of Tconv while promoting Treg induction. Given this background and the EPO-associated positive effects on disease severity in murine models of SLE, EPO may warrant further evaluation in clinical studies including SLE patients.

Notably, EPO administration carries the risk of thrombosis or stroke, especially in patients with a pro-thrombotic disease, like those with SLE. This highlights the potential utility of newer nonhematopoietic EPO-derivatives including carbamylated EPO or ARA290. Although some studies have demonstrated improved lupus nephritis disease activity in mouse models receiving ARA290 (82), others have found inconsistencies between EPO's and ARA290's effects, possibly highlighting the importance of both EPORs in disease pathophysiology $(75,79)$. Additional studies are needed to clarify the immunomodulating effects of these derivatives and their therapeutic role in SLE.

\section{AUTHOR CONTRIBUTIONS}

ME wrote manuscript the initial draft. CC participated in the manuscript writing. PC supervised the manuscript. All authors contributed to the article and approved the submitted version.

\section{FUNDING}

PC was supported by the National Institutes of Health (National Institute of Allergy and Infectious Diseases [NIAID]) R01 0255A141. The content is solely the responsibility of the authors and does not necessarily represent the official views of the National Institutes of Health. late manifestations in a cohort of 1,000 patients. Medicine. (2003) 82:299-308. doi: 10.1097/01.md.0000091181.93122.55

6. Wang F, Wang C, Tan C, Manivasagar M. Systemic lupus erythematosus in Malaysia: a study of 539 patients and comparison of prevalence and disease expression in different racial and gender groups. Lupus. (1997) 6:24853. doi: 10.1177/096120339700600306

7. Tektonidou MG, Dasgupta A, Ward MM. Risk of end-stage renal disease in patients with lupus nephritis, 1971-2015: a systematic review and bayesian meta-analysis. Arthritis Rheumatol. (2016) 68:1432-41. doi: 10.1002/art.39594

8. Contreras G, Mattiazzi A, Guerra G, Ortega LM, Tozman EC, Li H, et al. Recurrence of lupus nephritis after kidney transplantation. J Am Soc Nephrol. (2010) 21:1200-7. doi: 10.1681/ASN.2009101093

9. Muñoz LE, Lauber K, Schiller M, Manfredi AA, Herrmann M. The role of defective clearance of apoptotic cells in systemic autoimmunity. Nat Rev Rheumatol. (2010) 6:280-9. doi: 10.1038/nrrheum.2010.46

10. Lech M, Anders H-J. The Pathogenesis of Lupus Nephritis. J Am Soc Nephrol. (2013) 24:1357-66. doi: 10.1681/ASN.2013010026 
11. Nowling TK, Gilkeson GS. Mechanisms of tissue injury in lupus nephritis. Arthritis Res Ther. (2011) 13:1-9. doi: 10.1186/ar3528

12. Jin O, Kavikondala S, Sun L, Fu R, Mok MY, Chan A, et al. Systemic lupus erythematosus patients have increased number of circulating plasmacytoid dendritic cells, but decreased myeloid dendritic cells with deficient CD83 expression. Lupus. (2008) 17:654-62. doi: 10.1177/0961203308089410

13. Rönnblom L, Alm G V. A pivotal role for the natural interferon $\alpha$-producing cells (plasmacytoid dendritic cells) in the pathogenesis of lupus. J Exp Med. (2001) 194:F59-63. doi: 10.1084/jem.194.12.f59

14. Farkas L, Beiske K, Lund-Johansen F, Brandtzaeg P, Jahnsen FL. Plasmacytoid dendritic cells (natural interferon- $\alpha / \beta$-producing cells) accumulate in cutaneous lupus erythematosus lesions. Am J Pathol. (2001) 159:23743. doi: 10.1016/S0002-9440(10)61689-6

15. Rowland SL, Riggs JM, Gilfillan S, Bugatti M, Vermi W, Kolbeck R, et al. Early, transient depletion of plasmacytoid dendritic cells ameliorates autoimmunity in a lupus model. J Exp Med. (2014) 211:1977-91. doi: 10.1084/jem.20132620

16. Celhar T, Hopkins R, Thornhill SI, De Magalhaes R, Hwang SH, Lee HY, et al. RNA sensing by conventional dendritic cells is central to the development of lupus nephritis. Proc Natl Acad Sci USA. (2015) E6195204. doi: 10.1073/pnas.1507052112

17. Tsokos GC, Lo MS, Reis PC, Sullivan KE. New insights into the immunopathogenesis of systemic lupus erythematosus. Nat Rev Rheumatol. (2016) 12:716-30. doi: 10.1038/nrrheum.2016.186

18. Villar J, Segura E. Decoding the heterogeneity of human dendritic cell subsets. Trends Immunol. (2020) 41:1062-71. doi: 10.1016/j.it.2020.10.002

19. Ma C, Xia Y, Yang Q, Zhao Y. The contribution of macrophages to systemic lupus erythematosus. Clin Immunol. (2019) 207:19. doi: 10.1016/j.clim.2019.06.009

20. Ren Y, Tang J, Mok MY, Chan AWK, Wu A, Lau CS. Increased apoptotic neutrophils and macrophages and impaired macrophage phagocytic clearance of apoptotic neutrophils in systemic lupus erythematosus. Arthritis Rheum. (2003) 48:2888-97. doi: 10.1002/art.11237

21. Li J, Liu C-H, Xu D-L, Gao B. Significance of CD163-positive macrophages in proliferative glomerulonephritis. Am J Med Sci. (2015) 350:38792. doi: 10.1097/MAJ.0000000000000569

22. Iwata S, Tanaka Y. B-cell subsets, signaling and their roles in secretion of autoantibodies. Lupus. (2016) 25:850-6. doi: 10.1177/0961203316643172

23. Taher TE, Parikh K, Flores-Borja F, Mletzko S, Isenberg DA, Peppelenbosch $\mathrm{MP}$, et al. Protein phosphorylation and kinome profiling reveal altered regulation of multiple signaling pathways in b lymphocytes from patients with systemic lupus erythematosus. Arthritis Rheum. (2010) 62:241223. doi: 10.1002/art.27505

24. Lipsky PE. Systemic lupus erythematosus: an autoimmune disease of B cell hyperactivity. Nat Immunol. (2001) 2:764-6. doi: 10.1038/ni0901-764

25. Miyara M, Amoura Z, Parizot C, Badoual C, Dorgham K, Trad S, et al. Global natural regulatory $\mathrm{T}$ cell depletion in active systemic lupus erythematosus. J Immunol. (2005) 175:8392-400. doi: 10.4049/jimmunol.175. 12.8392

26. Crispín JC, Kyttaris VC, Terhorst C, Tsokos GC. T cells astherapeutic targets in SLE. Nat Rev Rheumatol. (2010) 6:317-25. doi: 10.1038/nrrheum.2010.60

27. Yang J, Chu Y, Yang X, Gao D, Zhu L, Yang X, et al. Th17 and natural treg cell population dynamics in systemic lupus erythematosus. Arthritis Rheum. (2009) 60:1472-83. doi: 10.1002/art.24499

28. Talaat RM, Mohamed SF, Bassyouni IH, Raouf AA. Th1/Th2/Th17/Treg cytokine imbalance in systemic lupus erythematosus (SLE) patients: correlation with disease activity. Cytokine. (2015) 72:146-53. doi: 10.1016/j.cyto.2014.12.027

29. Dolff S, Bijl M, Huitema MG, Limburg PC, Kallenberg CGM, Abdulahad WH. Disturbed Th1, Th2, Th17 and $\mathrm{T}$ reg balance in patients with systemic lupus erythematosus. Clin Immunol. (2011) 141:197-204. doi: 10.1016/j.clim.2011.08.005

30. Ma J, Yu J, Tao X, Cai L, Wang J, Zheng SG. The imbalance between regulatory and IL-17-secreting CD4+ T cells in lupus patients. Clin Rheumatol. (2010) 29:1251-8. doi: 10.1007/s10067-010-1510-7

31. Crispín JC, Oukka M, Bayliss G, Cohen RA, Van Beek CA, Stillman IE, et al. Expanded double negative $\mathrm{T}$ cells in patients with systemic lupus erythematosus produce IL-17 and infiltrate the kidneys. J Immunol. (2008) 181:8761-6. doi: 10.4049/jimmunol.181.12.8761
32. Chun H-Y, Chung J-W, Kim H-A, Yun J-M, Jeon J-Y, Ye Y-M, et al. Cytokine IL-6 and IL-10 as biomarkers in systemic lupus erythematosus. J Clin Immunol. (2007) 27:461-6. doi: 10.1007/s10875-007-9104-0

33. Bunn HF. Erythropoietin. Cold Spring Harb Perspect Med. (2013) 3:120. doi: 10.1101/cshperspect.a011619

34. Chateauvieux S, Grigorakaki C, Morceau F, Dicato M, Diederich M. Erythropoietin, erythropoiesis and beyond. Biochem Pharmacol. (2011) 82:1291-303. doi: 10.1016/j.bcp.2011.06.045

35. Ebert BL, Bunn HF. Regulation of the erythropoietin gene. Blood. (1999) 94:1864-77. doi: 10.1182/blood.V94.6.1864

36. Elliott S, Sinclair AM. The effect of erythropoietin on normal and neoplastic cells. Biol Targets Ther. (2012) 6:163-89. doi: 10.2147/BTT.S32281

37. Brines M, Grasso G, Fiordaliso F, Sfacteria A, Ghezzi P, Fratelli M, et al. Erythropoietin mediates tissue protection through an erythropoietin and common B-subunit heteroreceptor. Proc Natl Acad Sci USA. (2004) 101:14907-12. doi: 10.1073/pnas.0406491101

38. Brines M, Cerami A. Discovering erythropoietin's extra-hematopoietic functions: biology and clinical promise. Kidney Int. (2006) 70:24650. doi: 10.1038/sj.ki.5001546

39. Hand CC, Brines M. Promises and pitfalls in erythopoietin-mediated tissue protection: are nonerythropoietic derivatives a way forward? J Investig Med. (2011) 59:1073-82. doi: 10.2310/JIM.0b013e3181ed30bf

40. Bohlius J, Bohlke K, Castelli R, Djulbegovic B, Lustberg MB, Martino M, et al. Management of cancer-associated anemia with erythropoiesis-stimulating agents: ASCO/ASH clinical practice guideline update. J Clin Oncol. (2019) 37:1336-51. doi: 10.1200/JCO.18.02142

41. Drüeke TB, Parfrey PS. Summary of the KDIGO guideline on anemia and comment: reading between the (guide)line(s). Kidney Int. (2012) 82:95260. doi: $10.1038 / \mathrm{ki} .2012 .270$

42. Bohlius J, Schmidlin K, Brillant C, Schwarzer G, Trelle S, Seidenfeld J, et al. Recombinant human erythropoiesis-stimulating agents and mortality in patients with cancer: a meta-analysis of randomised trials. Lancet. (2009) 373:1532-42. doi: 10.1016/S0140-6736(09)60502-X

43. Pfeffer MA, Burdmann EA, Chen C-Y, Cooper ME, Zeeuw D de, Eckardt K-U, et al. A trial of darbepoetin alfa in type 2 diabetes and chronic kidney disease. N Engl J Med. (2009) 361:2019-32. doi: 10.1056/NEJMoa0907845

44. Tonia T, Mettler A, Robert N, Schwarzer G, Seidenfeld J, Weingart O, et al. Erythropoietin or darbepoetin for patients with cancer. Cochrane Database Syst Rev. (2012) 12:CD003407. doi: 10.1002/14651858.CD003407.pub5

45. Erbayraktar S, Grasso G, Sfacteria A, Xie Q, Coleman T, Kreilgaard M, et al. Asialoerythropoietin is a non-erythropoietic cytokine with broad neuroprotective activity in vivo. Proc Natl Acad Sci USA. (2003) 100:67416. doi: $10.1073 /$ pnas. 1031753100

46. Fiordaliso F, Chimenti S, Staszewsky L, Bai A, Carlo E, Cuccovillo I, et al. A non-erythropoietic derivative of erythropoietin protects the myocardium from ischemia-reperfusion injury. Proc Natl Acad Sci USA. (2005) 102:204651. doi: 10.1073/pnas.0409329102

47. Leist M, Ghezzi P, Grasso G, Bianchi R, Vilia P, Fratelli M, et al. Derivatives of erythropoitein that are tissue protective but not erythropoietic. Science. (2004) 305:239-42. doi: 10.1126/science. 1098313

48. Byts N, Sirén A-L. Erythropoietin: a multimodal neuroprotective agent. Exp Transl Stroke Med. (2009) 1:1-10. doi: 10.1186/2040-7378-1-4

49. Ehrenreich H, Weissenborn K, Prange H, Schneider D, Weimar $\mathrm{C}$, Wartenberg $\mathrm{K}$, et al. Recombinant human erythropoietin in the treatment of acute ischemic stroke. Stroke. (2009) 40:e64756. doi: 10.1161/STROKEAHA.109.564872

50. Tsai T-H, Lu C-H, Wallace CG, Chang W-N, Chen S-F, Huang C-R, et al. Erythropoietin improves long-term neurological outcome in acute ischemic stroke patients: a randomized, prospective, placebo-controlled clinical trial. Crit Care. (2015) 19:1-9. doi: 10.1186/s13054-015-0761-8

51. Borhani-Haghighi A, Ghodsi M, Razeghinejad MR, Mardani S, Mardani M, Nikseresht AR, et al. Erythropoietin for acute multiple sclerosis in patients with optic neuritis as a first demyelination event. Neurosciences. (2012) 17:151-5. doi: 10.3969/j.issn.1672-7347.2010.11.001

52. Diem R, Molnar F, Beisse F, Gross N, Drüschler K, Heinrich SP, et al. Treatment of optic neuritis with erythropoietin (TONE): a randomised, double-blind, placebo-controlled trial-study protocol. BMJ Open. (2016) 6:e010956. doi: 10.1136/bmjopen-2015-010956 
53. Aghdam KA, Sanjari MS, Falavarjani KG. Erythropoietin in ophthalmology: a literature review. J Curr Ophthalmol. (2016) 28:5-11. doi: 10.1016/j.joco.2016.01.008

54. Junk AK, Mammis A, Savitz SI, Singh M, Roth S, Malhotra S, et al. Erythropoietin administration protects retinal neurons from acute ischemia-reperfusion injury. Proc Natl Acad Sci USA. (2002) 99:10659-64. doi: 10.1073/pnas.152321399

55. Grimm C, Wenzel A, Groszer M, Mayser H, Seeliger M, Samardzija M, et al. HIF-1-induced erythropoietin in the hypoxic retina protects against lightinduced retinal degeneration. Nat Med. (2002) 8:718-24. doi: 10.1038/nm723

56. Lipšic E, Schoemaker RG, van der Meer P, Voors AA, van Veldhuisen DJ, van Gilst WH. Protective effects of erythropoietin in cardiac ischemia: from bench to bedside. J Am Coll Cardiol. (2006) 48:2161-7. doi: 10.1016/j.jacc.2006.08.031

57. Ott I, Schulz S, Mehilli J, Fichtner S, Hadamitzky M, Hoppe K, et al. Erythropoietin in patients with acute ST-segment elevation myocardial infarction undergoing primary percutaneous coronary intervention: a randomized, double-blind trial. Circ Cardiovasc Interv. (2010) 3:40813. doi: 10.1161/CIRCINTERVENTIONS.109.904425

58. Najjar SS, Rao S V, Melloni C, Raman S V, Povsic TJ, Melton L, et al. Intravenous erythropoietin in patients with ST-segment elevation myocardial infarction. JAMA. (2011) 305:1863-72. doi: 10.1001/jama.2011.592

59. Ali-Hassan-Sayegh S, Mirhosseini SJ, Tahernejad M, Mahdavi P, Haddad F, Shahidzadeh A, et al. Administration of erythropoietin in patients with myocardial infarction: does it make sense? An updated and comprehensive meta-analysis and systematic review. Cardiovasc Revascularization Med. (2015) 16:179-89. doi: 10.1016/j.carrev.2015.01.008

60. Westenfelder C, Biddle DL, Baranowski RL. Human, rat, and mouse kidney cells express functional erythropoietin receptors. Kidney Int. (1999) 55:80820. doi: 10.1046/j.1523-1755.1999.055003808.x

61. Chatterjee PK. Pleiotropic renal actions of erythropoietin. Lancet. (2005) 365:1890-2. doi: 10.1016/S0140-6736(05)66622-6

62. Tögel FE, Ahlstrom JD, Yang Y, Hu Z, Zhang P, Westenfelder C. Carbamylated erythropoietin outperforms erythropoietin in the treatment of AKI-on-CKD and other AKI models. J Am Soc Nephrol. (2016) 27:3394404. doi: 10.1681/ASN.2015091059

63. Elliott S, Tomita D, Endre Z. Erythropoiesis stimulating agents and reno-protection: a meta-analysis. BMC Nephrol. (2017) 18:1-16. doi: 10.1186/s12882-017-0438-4

64. Katavetin P, Tungsanga K, Eiam-Ong S, Nangaku M. Antioxidative effects of erythropoietin. Kidney Int. (2007) 72:S10-5. doi: 10.1038/sj.ki.5002482

65. Bittorf T, Seiler J, Lüdtke B, Büchse T, Jaster R, Brock J. Activation of STAT5 during EPO-directed suppression of apoptosis. Cell Signal. (2000) 12:23-30. doi: 10.1016/S0898-6568(99)00063-7

66. Wiese L, Hempel C, Penkowa M, Kirkby N, Kurtzhals JAL. Recombinant human erythropoietin increases survival and reduces neuronal apoptosis in a murine model of cerebral malaria. Malar J. (2008) 7:1-10. doi: 10.1186/1475-2875-7-3

67. Sirén AL, Fratelli M, Brines M, Goemans C, Casagrande S, Lewczuk $\mathrm{P}$, et al. Erythropoietin prevents neuronal apoptosis after cerebral ischemia and metabolic stress. Proc Natl Acad Sci USA. (2001) 98:4044-9. doi: 10.1073/pnas.051606598

68. Choi D, Schroer SA, Lu SY, Wang L, Wu X, Liu Y, et al. Erythropoietin protects against diabetes through direct effects on pancreatic $\beta$ cells. J Exp Med. (2010) 207:2831-42. doi: 10.1084/jem.20100665

69. He H, Wu T, Xiong J, Chen K, Mo Z. Effect of erythropoietin on the proliferation and apoptosis of neonatal porcine islet cells. J Cent South Univ Med Sci. (2010) 35:1115-22.

70. Cantarelli C, Angeletti A, Cravedi P. Erythropoietin, a multifaceted protein with innate and adaptive immune modulatory activity. Am J Transplant. (2019) 19:2407-14. doi: 10.1111/ajt.15369

71. Wei X, Li Y, Sun X, Zhu X, Feng Y, Liu J, et al. Erythropoietin protects against murine cerebral malaria through actions on host cellular immunity. Infect Immun. (2014) 82:165-73. doi: 10.1128/IAI.00929-13

72. Agnello D, Bigini P, Villa P, Mennini T, Cerami A, Brines ML, et al. Erythropoietin exerts an anti-inflammatory effect on the CNS in a model of experimental autoimmune encephalomyelitis. Brain Res. (2002) 952:12834. doi: 10.1016/S0006-8993(02)03239-0
73. Nairz M, Schroll A, Moschen AR, Sonnweber T, Theurl M, Theurl I, et al. Erythropoietin contrastingly affects bacterial infection and experimental colitis by inhibiting nuclear factor- $\kappa \mathrm{B}$-inducible immune pathways. Immunity. (2011) 34:61-74. doi: 10.1016/j.immuni.2011.01.002

74. Luo B, Gan W, Liu Z, Shen Z, Wang J, Shi R, et al. Erythropoeitin signaling in macrophages promotes dying cell clearance and immune tolerance. Immunity. (2016) 44:287-302. doi: 10.1016/j.immuni.2016.01.002

75. Cravedi P, Manrique J, Hanlon KE, Reid-Adam J, Brody J, Prathuangsuk P, et al. Immunosuppressive effects of erythropoietin on human alloreactive $\mathrm{T}$ cells. J Am Soc Nephrol. (2014) 25:2003-15. doi: 10.1681/ASN.2013090945

76. Zhang Z, Liu D, Zhang X, Wang X. Erythropoietin treatment ameliorates lupus nephritis of MRL/lpr mice. Inflammation. (2018) 41:1888-99. doi: 10.1007/s10753-018-0832-5

77. Liu Y, Luo B, Han F, Li X, Xiong J, Jiang M, et al. Erythropoietin-derived non-erythropoietic peptide ameliorates experimental autoimmune neuritis by inflammation suppression and tissue protection. PLOS ONE. (2014) 9:e90942. doi: 10.1371/journal.pone.0090942

78. Donadei C, Angeletti A, Cantarelli C, D’Agati VD, La Manna G, Fiaccadori E, et al. Erythropoietin inhibits SGK1-dependent Th17 cell induction and Th17 cell-dependent kidney disease. JCI Insight. (2019) 4:119. doi: $10.1172 /$ jci.insight. 127428

79. Purroy C, Fairchild RL, Tanaka T, Baldwin WM, Manrique J, Madsen JC, et al. Erythropoietin receptor-mediated molecular crosstalk promotes $\mathrm{T}$ cell immunoregulation and transplant survival. J Am Soc Nephrol. (2017) 28:237792. doi: 10.1681/ASN.2016101100

80. Cuzzocrea S, Mazzon E, Paola R Di, Genovese T, Patel NSA, Britti D, et al. Erythropoietin reduces the degree of arthritis caused by type II collagen in the mouse. Arthritis Rheum. (2005) 52:940-50. doi: 10.1002/art.20875

81. Lifshitz L, Prutchi-Sagiv S, Avneon M, Gassmann M, Mittelman M, Neumann D. Non-erythroid activities of erythropoietin: functional effects on murine dendritic cells. Mol Immunol. (2009) 46:713-21. doi: 10.1016/j.molimm.2008.10.004

82. Huang B, Jiang J, Luo B, Zhu W, Liu Y, Wang Z, et al. Non-erythropoietic erythropoietin-derived peptide protects mice from systemic lupus erythematosus. J Cell Mol Med. (2018) 22:3330-9. doi: 10.1111/jcmm.13608

83. Lisowska KA, Debska-Slizień A, Bryl E, Rutkowski B, Witkowski JM. Erythropoietin receptor is expressed on human peripheral blood $\mathrm{T}$ and $\mathrm{B}$ lymphocytes and monocytes and is modulated by recombinant human erythropoietin treatment. Artif Organs. (2010) 34:654-62. doi: 10.1111/j.1525-1594.2009.00948.x

84. Luo B, Jiang $M$, Yang X, Zhang Z, Xiong J, Schluesener HJ, et al. Erythropoietin is a hypoxia inducible factor-induced protective molecule in experimental autoimmune neuritis. Biochim Biophys Acta. (2013) 1832:126070. doi: 10.1016/j.bbadis.2013.04.015

85. Yuan RR, Maeda Y, Li W, Lu W, Cook S, Dowling P. Erythropoietin: a potent inducer of peripheral immuno/inflammatory modulation in autoimmune EAE. PLoS ONE. (2008) 3:e1924. doi: 10.1371/journal.pone.0001924

86. Tzioufas AG, Kokori SI, Petrovas CI, Moutsopoulos HM. Autoantibodies to human recombinant erythropoietin in patients with systemic lupus erythematosus: correlation with anemia. Arthritis Rheum. (1997) 40:22126. doi: 10.1002/art.1780401216

87. Voulgarelis M, Kokori SIG, Ioannidis JPA, Tzioufas AG, Kyriaki D, Moutsopoulos HM. Anaemia in systemic lupus erythematosus: aetiological profile and the role of erythropoietin. Ann Rheum Dis. (2000) 59:21722. doi: 10.1136/ard.59.3.217

88. Schett G, Firbas U, Fu W, Hiesberger H, Winkler S, Wachauer D, et al. Decreased serum erythropoietin and its relation to anti-erythropoietin antibodies in anaemia of systemic lupus erythematosus. Rheumatology. (2001) 40:424-31. doi: 10.1093/rheumatology/40.4.424

89. Luo XY, Yang M-H, Peng P, Wu L-J, Liu Q-S, Chen L, et al. Anti-erythropoietin receptor antibodies in systemic lupus erythematosus patients with anemia. Lupus. (2013) 22:121-7. doi: 10.1177/09612033124 63980

90. Hara A, Furuichi K, Yamahana J, Yasuda H, Iwata Y, Sakai $\mathrm{N}$, et al. Effect of autoantibodies to erythropoietin receptor in systemic lupus erythematosus with biopsy-proven lupus nephritis. J Rheumatol. (2016) 43:1328-34. doi: 10.3899/jrheum.15 1430 
91. Li W, Titov AA, Morel L. An update on lupus animal models. Curr Opin Rheumatol. (2017) 29:434-41. doi: 10.1097/BOR.0000000000000412

92. Santiago-Raber ML, Laporte C, Reininger L, Izui S. Genetic basis of murine lupus. Autoimmun Rev. (2004) 3:33-9. doi: 10.1016/S1568-9972(03)00062-4

93. Gulinello M, Putterman C. The MRL/lpr mouse strain as a model for neuropsychiatric systemic lupus erythematosus. J Biomed Biotechnol. (2011) 2011:1-15. doi: 10.1155/2011/207504

94. Gómez-puerta JA, Waikar SS, Solomon DH, Liu J, Alarcon GS, Winkelmayer WC, et al. Erythropoiesis-stimulating agent use among patients with lupus nephritis approaching end-stage renal disease. J Clin Cell Immunol. (2013) 4:179. doi: 10.4172/2155-9899.1000179
Conflict of Interest: The authors declare that the research was conducted in the absence of any commercial or financial relationships that could be construed as a potential conflict of interest.

Copyright $(02021$ Eswarappa, Cantarelli and Cravedi. This is an open-access article distributed under the terms of the Creative Commons Attribution License (CC BY). The use, distribution or reproduction in other forums is permitted, provided the original author(s) and the copyright owner(s) are credited and that the original publication in this journal is cited, in accordance with accepted academic practice. No use, distribution or reproduction is permitted which does not comply with these terms. 